\title{
Aplikasi Web Registrasi Advertising Menggunakan Metode Paid-To-Promote
}

\author{
Rudi Prasetya $^{1}$, Danang Sutrisno ${ }^{2}$ \\ ${ }^{1,2}$ Teknik Informatika, Universias Indraprasta PGRI, Jakarta Selatan, Indonesia \\ e-mail: ${ }^{1}$ rudiprasetya1@gmail.com, ${ }^{2}$ dngs3674@gmail.com
}

Submitted Date: March 04 ${ }^{\text {th }}, 2021$

Revised Date: June 04 ${ }^{\text {th }}, 2021$
Reviewed Date: June 02 ${ }^{\text {nd }}, 2021$

Accepted Date: June $15^{\text {th }}, 2021$

\begin{abstract}
The use of websites for advertising activities is rarely found in Indonesia. Most of the websites developed are still for commercial purposes and some are free but limit certain facilities. This study aims to develop a website that can facilitate these needs. The website that is built is a website that can be used to help display advertisements from advertisers and provide opportunities for people who want to help researchers in serving advertisements with certain benefits. The system will pay members who promote ads even if they only see the ad. Website development begins with designing a website database. The next stage is designing a website using a codeigniter framework. This web development model uses the concept of model, view, and controller (MVC) in codeigniter. Website model development is becoming faster and more structured. The results of this web design research are used for community social activities to earn income via the internet.
\end{abstract}

Keywords: Website; Paid-To-Promote; Codeigniter; Advertising

\section{Abstrak}

Pemanfaatan website untuk kegiatan periklanan jarang ditemukan di Indonesia. Sebagian besar website yang dikembangkan masih bertujuan komersial dan adapun yang bersifat free tetapi membatasi suatu fasilitas tertentu. Penelitian ini bertujuan untuk mengembangkan website yang dapat memfasilitasi kebutuhan tersebut. Website yang dibangun adalah website yang dapat digunakan untuk membantu manayangkan iklan dari pemilik iklan dan memberi kesempatan kepada masyarakat yang ingin ikut membantu peneliti dalam menayangkan iklan dengan mendapatkan keuntungan tertentu. Sistem akan membayar member yang mempromosikan iklan walaupun hanya dilihat saja iklanya. Pengembangan website dimulai dengan perancangan database website. Tahap berikutnya merancang website dengan menggunakan framework codeigniter. Model pengembangan web ini menggunakan konsep model, view, dan controller (MVC) pada codeigniter. Pengembangan model website menjadi lebih cepat dan terstruktur. Hasil penelitian perancangan web ini digunakan untuk kegiatan sosial masyarakat untuk mendapatkan pendapatan melalui internet.

Kata Kunci: Website; Paid-To-Promote; Codeigniter; Iklan

\section{Pendahuluan}

Seiring dengan meningkatnya perkembangan teknologi internet, bentuk kegiatan yang dapat dilakukan melalui internet juga mengalami perubahan. Dengan adanya internet dan website banyak informasi yang dapat diakses lebih mudah dan tersebar lebih cepat sehingga lebih efisien (Yulianti, Saifudin, Haryono, Zulfikar, \& Desyani, 2020). Saat ini internet dapat dimanfaatkan untuk semacam Network Advertising berbasis Paid to Promote. Model bisnis ini merupakan program mendapatkan uang dollar bekerja dengan sistem Cost Per Mile. Pengguna akan mendapatkan bayaran walaupun iklan tidak dibuka.

Peneliti sebelumnya merupakan salah satu anggota yang telah terdaftar disitus-situs penyedian iklan maju seperti Google Adsense, Adf.ly, Addfocus, dsb. Namun dalam kesempatan ini peneliti ingin membuat kembali aplikasi berbasis Paid to Promote yang dapat membuka kesempatan kepada para orang lain untuk ikut membantu dalam menayangkan iklan yang dimiliki peneliti. Keuntungan masyarakat yang ikut membantu 
peneliti diberikan point yang dapat ditukarkan dengan uang satuan $\$$ (dolar).

Lalu peran peneliti di sini adalah sebagai Distributor iklan, di mana seluruh iklan yang berada di tangan peneliti adalah milik pihak ketiga, keuntungan peneliti sebagai distributor adalah akan diberikan keuntungan berdasarkan ketentuan dari pihak ketiga yang dimaksud adalah penyedia jasa iklan maju pada umumnya seperti Google Adsense (Enterprise, 2008), Adf.ly, dan penyedia iklan lainya.

Bentuk layanan di dalam website ini adalah memberikan kesempatan pada masyarakat yang ingin membantu peneliti dalam menayangkan iklan (Kasali, 2005). Tahap pertama masyarakat harus mendaftar melalui situs yang telah disediakan peneliti, yaitu situs ShortAds dan ketika masyarakat telah menyelesaikan tahap pendaftaran maka masyarakat sudah menjadi Member di ShortAds (Rusdianto, 2010). Member diberikan uang dengan satuan dolar apabila berhasil mendapatkan seribu point earning. Seribu point earning dicapai dengan cara menayangkan iklan yang diberikan peneliti sebanyak seribu kali tayang, jadi setiap satu kali iklan tayang maka member akan meraih satu point earning.

Seribu Point Earning merupakan syarat minimum point yang diajukan peneliti kepada member untuk ditukarkan ke uang satuan \$(dolar) (Amal Nur Ngazis, 2015). Lalu proses pembayaran dikirim melalui email paypal yang diajukan member. Disini peneliti menerapkan jadwal pembayaran setiap hari sabtu perbulan.

Penelitian ini bertujuan membuat sebuah website untuk membantu manampilkan iklan dari pemilik iklan dan memberi kesempatan kepada masyarakat yang ingin ikut membantu peneliti dalam menayangkan iklan dengan keuntungan tertentu. Dengan Hal tersebut diharapkan dapat memberikan kontribusi langsung kepada masyarakat maupun pemilik iklan.

\section{Metode Penelitian}

Penelitian ini mengembangkan website dengan framework Codeigniter (Griffiths, 2010) (Myer, 2008). Bahasa pemrorgraman PHP (Sakur, 2010) dan database MySQL merupakan dasar dari model ini. Tahap pengembangan awal dengan menganalisis kebutuhan sistem. Kegiatan ini dilakukan dengan menganalisis kebutuhan pengguna. Analisis tersebut menjadi dasar dalam perancangan website.

Rancangan halaman website kemudian dibentuk dengan model framework menjadi halaman website (Ducket, 2011). Menggunakan bantuan browser agar dapat menampilkan hasil proses pembuatan dengan model framework tadi (Henick, 2010). Hasil rancangan website manjadi lebih dinamis dan responsif.

Tahapan selanjutnya adalah pembuatan website secara keseluruhan. Tahapan ini mengembangkan rangkaian sistem website berupa pendaftaran, login, pembayaran dan lainnya.

Setelah pengembangan dilanjutkan dengan pengujian, karena pengujian bertujuan untuk memastikan bahwa semua proses sudah berfungsi sesuai dengan kebutuhan yang ditetapkan (Muslimin, et al., 2020). Simulasi pengujian fungsi-fungsi website agar semua fungsi berjalan dengan baik dan benar. Tahapan pengujian dengan kuisioner berisi pertanyaan untuk penguji. Hasil pengujian kemudian dijadikan dasar perbaikan website.

Kegiatan pemasaran di internet adalah segala usaha yang dilakukan memasarkan produk atau jasa menggunakan media Internet (Sproul, 2007). Teknologi Internet membantu kegiatan secara konvensional menjadi kegiatan secara elektronik sehingga muncul istilah seperti halnya: e-surat, ebusiness, e-gov, e-society.

Pemasaran melalui media Internet umumnya berhubungan dengan produk periklanan, pencarian prospek atau pembeli dan penelitian kalimat pemasaran. Pemasaran internet berupa kegiatan pembuatan desain web, banner iklan, promosi menggunakan mesin pencari, iklan melalui surat elektronik, pemasaran afiliasi, iklan interaktif dan lainnya.

Salah satu pemasaran internet yang efektif menggunakan SEO (optimasi mesin pencari), social media dan iklan berbayar per-klik. Bermacam strategi perilkanan tersebut memerlukan pembelajaran untuk mengetahui lebih jauh tentang pemasaran di internet.

\section{Perancangan Sistem}

Logika cara kerja website ini digambarkan menggunakan UML. Diagram Akticitas di gunakan untuk menggamarkan bisnis proses sistem seperti pada tampilan berikut:

\section{a. Activity Diagram Pendaftaran}

Flowchart pendaftaran digunakan untuk menampilkan alur proses pendaftaran yang dilakukan pengunjung website hingga menjadi member. Formulir Pendaftaaran terletak disebelah kanan halaman awal ShortAds. Fomulir tersebut harus diisi sesuai dengan 
pertanyaan yang ada. Gambar 1 menampilkan flowchart pendafaran tersebut.

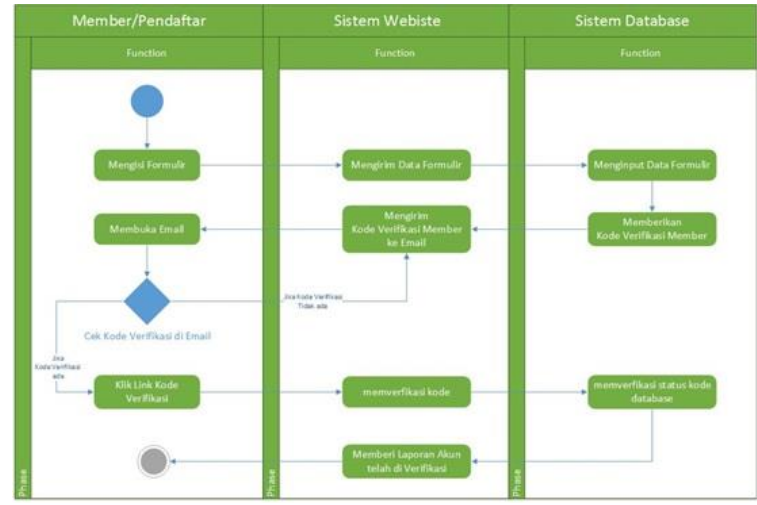

Gambar 1 Diagram Aktifitas Pendaftaran

Pada gambar 1 menjelaskan aktifitas registrasi pendaftaran untuk menjadi anggota. Proses pendaftaran ini dilakukan dengan membuar akun diwebsite dengan mengisi data aku secara lengkap sehingga data kita akan tercatat didalam database sistem.

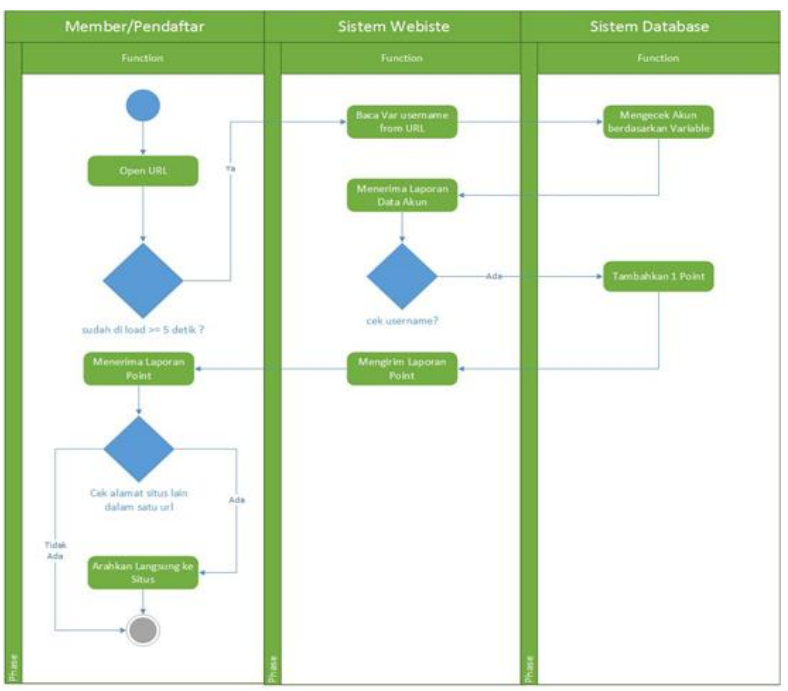

Gambar 2 Diagram Aktifitas Pendapatan

Pada gambar 2 adalah proses kita mendapakan keuntungan dari aktifitas kita menjadi anggota web iklan. Setiap periode tertentu kita mendapakan keuntungan berupa uang yang akan dikirim secara langsung ke rekening yang kita daftarkan.

\section{b. Activity Diagram - Paid URL}

Gambar 2 Activity Diagram Pendaptan ini menjelaskan bagaimana member bisa mendapatkan point yang ditukarkan uang dolar nantinya. Member harus mengakses URL miliknya sendiri yang tersedia di menu paid_url di halaman khusus member (Member Page). Ketika member atau siapapun berhasil mengakses URL tersebut selama 5 detik maka pemilik URL dari member itu mendapatkan 1 poin dari sistem. Gambar 2 menampilkan Activity Diagram Paid URL tersebut.

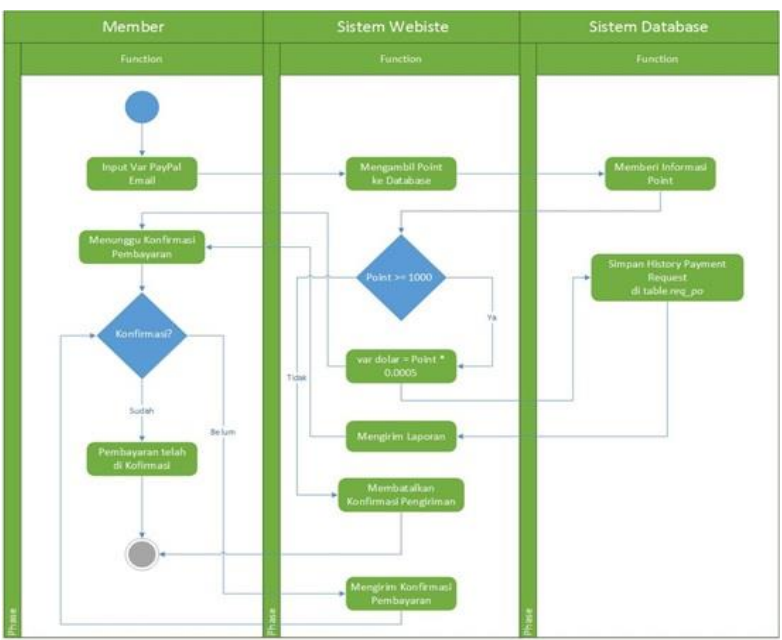

Gambar 3 Diagram Aktifitar Penerimaan

Gambar 3 adalah aktifitas jika kita menarik pendapatan yang kita peroleh dalam periode tertetentu. Pendapatan yang kita peroleh akan dikirim ke rekening kita secara langsung dan kita bisa menarik secara bebas.

Gambar 3 Activity Diagram Penerimaan digunakan pada saat member memiliki point sebanyak 1000 point, lalu member ingin menukarkan point tersebut dengan mata uang dolar. Gambar 3 menampilkan Activity Diagram unggah artikel berita tersebut.

\section{c. Activity Diagram Convert}

Gambar 4 merupakan Diagram ER website ShortAds memiliki 6 buah entitas, User/Member, Administrator Web, Earning, Advertisement, News, serta Payment Request. Entitas User/Member berelasi dengan entitas earning melalui proses relationship mendapatkan yang dilakukan oleh User/Member. Kardinalitasnya adalah banyak User/Member bisa mendapatkan banyak Earning. Entitas User/Member juga berelasi dengan entitas Payment Request melalui aktivitas mengajukan kepada entitas Payment Request. Kardinalitasnya adalah banyak akun User/Member bisa mendapatkan banyak Earning. 


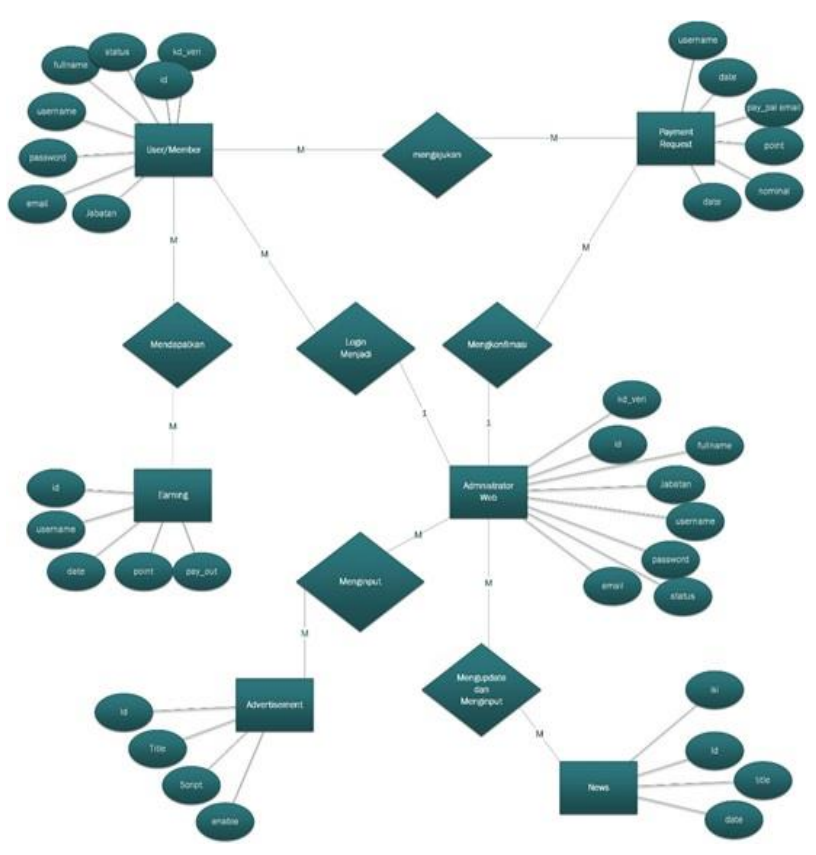

Gambar 4. Diargam Relasi Entitas Sistem

Tahapan awal yang dilakukan dalam desain aplikasi website ShortAds adalah membuat rancangan website secara keseluruhan. Perancangan tersebut dilakukan dengan cara membuat dan merancang storyboard, struktur navigasi, desain antarmuka website, desain basis data, serta alur program. Berikut ini adalah penjelasan tahapan perancangan desain aplikasi website

Dalam tahapan perancangan website ShortAds, peneliti membuat sebuah storyboard yang dirancang untuk menggambarkan alur proses interaksi pengunjung dengan sistem website. Storyboard ini akan menjelaskan langkah-langkah yang dilakukan pengunjung mulai dari masuk ke dalam halaman utama sampai dengan selesai melakukan proses pendaftaran dan menjadi anggota ShortAds. Gambar yang peneliti gunakan dalam storyboard ini merupakan screenshoot yang peneliti ambil dalam pada saat website sudah selesai dibuat dan diakses.

Halaman pertama yang dilihat pengunjung ketika memasuki website adalah halaman home. Di dalam halaman tersebut terdapat ilustrasi melalui image slider yang menjelaskan bagaimana website tersebut memproses pembayaran. serta disebelah kiri yang terdapat form registrasi.

Gambar 5 merupakan tampilan halaman utama sistem. Tampilan halaman utama ini berisi menu-menu sistem yang bisa ditunakan oleh pengguna.

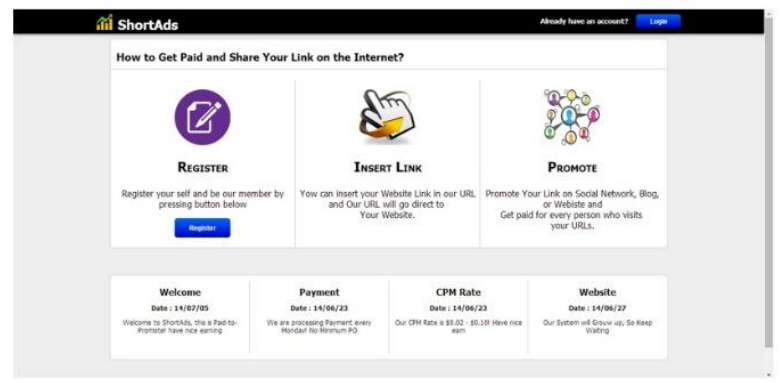

Gambar 5. Halaman Utama Sistem

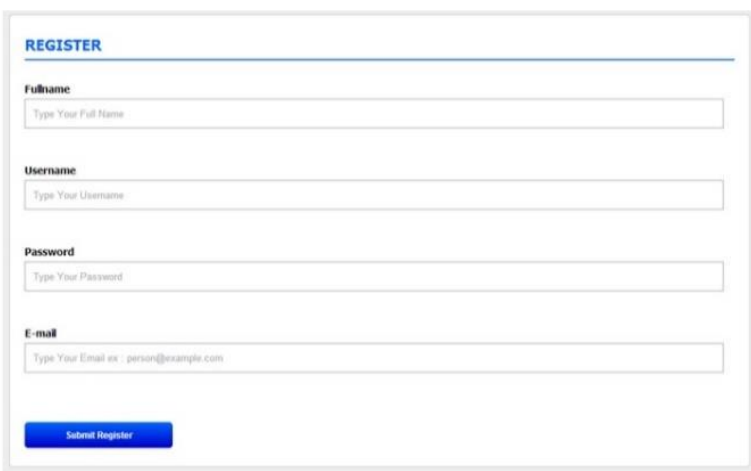

Gambar 6. Halaman Pendaftaran Akun

Pada Gambar 6 dijelaskan formulir pendaftaran pengguna jika belum memiliki akun. Pengguna wajib memberikan alamat email untuk mendapatkan verifikasi akun yang dikirim otomatis oleh sistem ke alamat email yang dicantumkan.
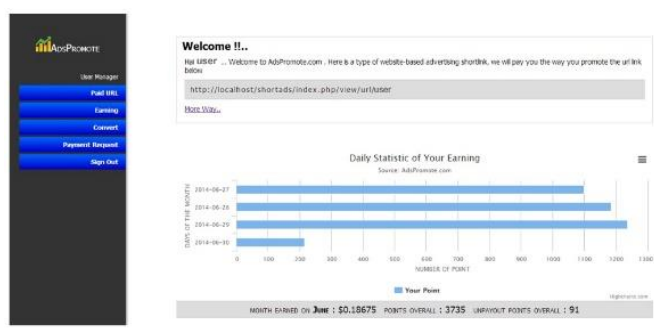

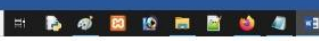

Gambar 7. Halaman Dasboard Sistem

Gambar 7 menjelaskan setelah Member berhasil login kemudian menuju ke halaman khusus member yaitu halaman user_page_v. User mendapatkan petunjuk bagaimana caranya member dapat mendapatkan uang dari website ShortAds. Halaman ini terdapat grafik yang berfungsi menunjukkan perbandingan pendapatan perharinya dalam jangka waktu sebulan.

Pada halaman Gambar 8 terdapat menu saat mengklik menu tombol Paid_URL terdapat maka akan muncul halaman paid_url di sampingnya. Halaman ini merupakan petunjuk bagaimana 
caranya agar Member menghasilkan point yang ditukarkan uang beramata uang dolar.

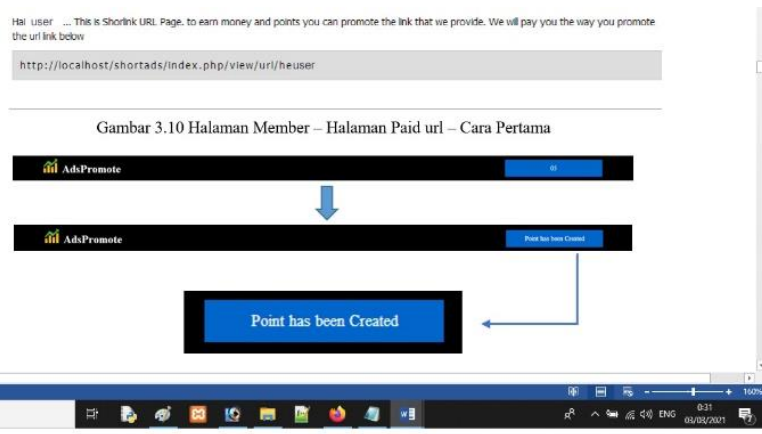

Gambar 8. Halaman Dasboard sistem

Cara pertamanya sesuai yang ditunjukan gambar 8 bahwa Member cukup mengakses url didalam teks berbackround warna abu-abu, lalu saat Member mengakses halaman tersebut maka akan muncul halaman baru, halaman tersebut bernama Page Promote.

Halaman Page Promote memberikan informasi Member Point sebanyak 1 Point denga syarat halaman tersebut berhasil dibuka selama 5 detik sampai memberikan pesan "Point has been Created" seperti pada gambar 8 .

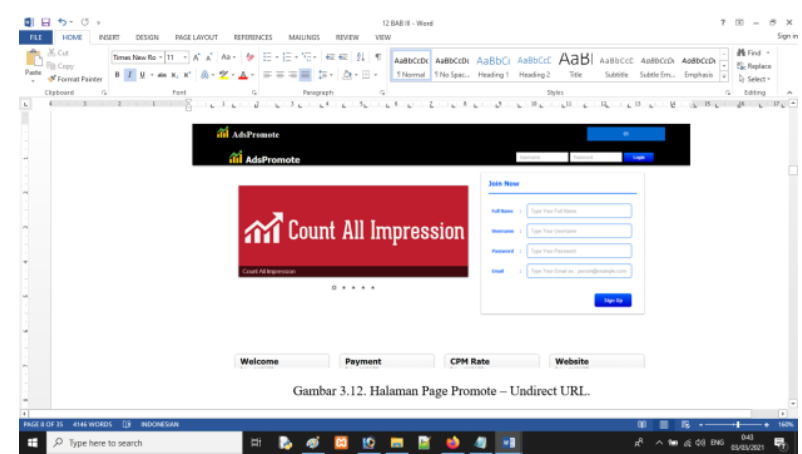

Gambar 9. Halaman Promosi

Selanjutnya pada Cara kedua yaitu Direct URL, cara ini tidak beda jauh dengan cara pertama hanya saja cara kedua adalah mempromosikan link URL adalah dengan menyisipkan alamat suatu website di ujung URL.

menjadi Go To Site, Klik tombol Go To Site maka secara otomatis web browser akan menuju ke google.com Seperti pada gambar 3.14

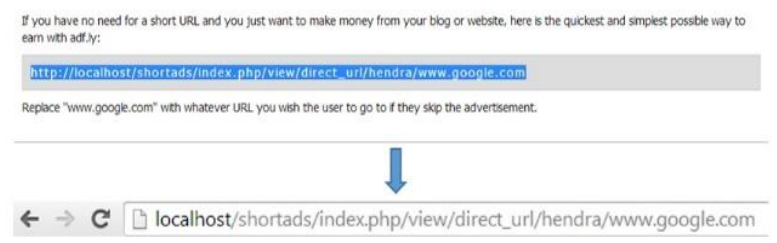

Gambar 10. Layar Promosi

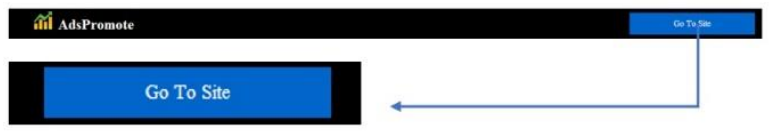

Gambar 11. Layar Kembali

Penjelasan Gambar 10 dan 11 adaalah cara ini cukup efektif untuk digunakan oleh kalangan orang yang ingin mengahasilkan uang melalui suatu Blog atau Website. Sebagai contoh Pada gambar 10 menyisipkan alamat URL Google dan tunggu sampai teks detiknya berubah kata menjadi Go To Site, Klik tombol Go To Site maka secara otomatis web browser akan menuju ke google.com Seperti pada Gambar 11

\section{Kesimpulan}

Website ShortAds telah selesai dibangun dengan menggunakan framework codeigniter. Hasil pengujian dan hasil survey pada penelitian selama proses pengembangan, dapat disimpulkan fungsionalitas website sudah terpenuhi. Website dapat mempromosikan iklan yang dititipkan pemilik iklan kepada Administrator Website ShortAds dan mempromosikan iklannya melalui aktifitas Member Webiste ShortAds.

Dalam proses pengembangan website, framework codeigniter sangat membantu peneliti dalam proses pembuatan website. Proses pembuatan website dengan menggunakan framework codeigniter dapat dilakukan dengan lebih cepat daripada harus menggunakan bahasa pemrograman php murni. Selain itu, kode program yang digunakan dalam pembuatan website menjadi lebih terstruktur dan mudah untuk dipahami oleh pemrogram yang lain.

\section{Referensi}

Amal Nur Ngazis, A. T. (2015, 04 01). Seksinya Iklan Digital 2020 Diprediksi Capai Rp 91 Triliun. Retrieved from teknologi.news.viva.co.id: teknologi.news.viva.co.id

Ducket, J. (2011). Ducket, Jon, HTML \& CSS: Design and Build Website. Indianapolis: John Wiley \& Sons, Inc.

Enterprise, J. (2008). Google AdSense untuk Pemula. Jakarta: PT Elex Media Komputindo.

Griffiths, A. (2010). Codeigniter 1.7 Professional Development. Birmingham: Packt Publishing.

Henick, B. (2010). HTML \& CSS: The Good Parts, Sebastopol: O'Reilly Media.

Kasali, R. (2005). Manajemen Periklanan Konsep dan Aplikasinya. Jakarta: PT Temprint. .

Muslimin, D. B., Kusmanto, D., Amilia, K. F., Ariffin, M. S., Mardiana, S., \& Yulianti, Y. (2020). 
Pengujian Black Box pada Aplikasi Sistem Informasi Akademik Menggunakan Teknik Equivalence Partitioning. Jurnal Informatika Universitas Pamulang, 5(1), 19-25. doi:10.32493/informatika.v5i1.3778

Myer, T. (2008). Professional Codeigniter. Indianapolis: Wiley Publishing,Inc.

Rusdianto, D. (2010). Adsense Weapons. Bandung: Oase Media.

Sakur, S. B. (2010). PHP 5 Pemrograman Berorientasi Objek (Konsep dan Implementasi). Yogyakarta: Andi.

Sproul, B. (2007). Community Effort in Online Groups. New York: Paper 90

Yulianti, Y., Saifudin, A., Haryono, W., Zulfikar, A. F., \& Desyani, T. (2020). Pengembangan dan Sosialisasi Website untuk Meningkatkan Penyebaran Informasi SMP Islam Madinatul I'lmi Ciputat-Tangerang Selatan. KOMMAS: Jurnal Pengabdian Kepada Masyarakat, 1(1), 16-24. 